\title{
Analysis on Impacts of High Temperature on Porosity and Compressive Quality of FC
}

\author{
C. Giri Prasad ${ }^{1}$, Dr. Ajay Swarup ${ }^{2}$ \\ ${ }^{1}$ Research Scholar, Department of Civil Engineering, Sri Satya Sai University of Technology and Medical Sciences, Sehore, Bhopal. \\ Madhya Pradesh, India \\ ${ }^{2}$ Professor, Department of Civil Engineering, Sri Satya Sai University of Technology and Medical Sciences, Sehore, Bhopal. Madhya \\ Pradesh, India
}

\begin{abstract}
Urbanization and modern-day headway in India wishes to concentrate on development methodology of thruways, railroads, air terminals and personal systems. This research taken street development, street renovation making use of BC soil and BC soil arrive. $B C$ soil (exclusive homes) and froth strong combo with black-top and cement for the upkeep there are little splits within the pavement (facet of the road) and the pothole-stuffed street is reduce off for fixes. Some method arrangements in reality like constructing extra roads are possibly no longer going to assist. Researchers are handling materials that fix themselves and are targeting of the maximum crucial materials in basis: black-top and urban. In India On a everyday, 3 lakh square km sector is anchored by Black cotton soil, Black cotton soil carries a dust mineral called Montmorillonite that is having a tough to overlook direct of swelling inner seeing clamminess and making shrinkage parts in dry season. Because of volumetric alternate in direct the shape created on such soils will encounter differential settlements, elements in systems or overall pummeling of the structure at any fee the systems can be based totally on this sort of soil via treating the broad soil with a non-large fabric. This ought to be plausible by the usage of ground enhancement framework like mechanical amendment, synthetic alternate, setting and warming, bracing earth technique, etc. In this text we learned approximately the effect of High temperature on Porosity and Compressive Quality of Foam Concrete. In this paper, The unstressed check system was grasped for solace. In the unstressed take a look at, the test become warmed, without preload, at an immovable charge to the destined temperature. While keeping up the intention temperature, stack changed into associated at a counseled rate till check disillusionment. The porosity could alongside those strains be a primary concept affecting the fabric properties of FC and a begin to finish observe this angle is basic to choose the associations among porosity and fabric homes Two diverse electric furnaces had been used for warming the FC courses to the various persevering with kingdom temperatures. The three reproduction trial of every arrangement gave extremely reliable effects so the everyday effects is probably utilized. Two diverse electric furnaces were used for warming the FC courses to the numerous persevering with state temperatures. It provides the compressive best and institutionalized compressive great of FC at unmistakable temperatures.
\end{abstract}

Keywords: Black Cotton Soil, Foam Concrete, Fly Ash

\section{Introduction}

The improvement of transportation foundation is the way to in general advancement of a nation. For nations like India, where assets are constrained, the significance of country roads is to be exceedingly underlined. The subgrade, which is the base most layer of the pavement, is comprised of compacted soil thus additionally for the expressway and railroad dikes the road arrangement is chosen dependent on numerous variables of which one is the accessibility of good soil along the proposed arrangement. In early days, territories having feeble soil stores are evaded while repairing the arrangement. However, with shortage of land and different assets, we don't have the decision of land and thus roads and dikes must be based on powerless soil stores [1].Black cotton soil is conceivably broad soil with montmorillonite as essential clay mineral and are portrayed by outrageous hardness and profound cracks when dry with inclination for hurling amid procedure of wetting. Road beds made up of such soils when exposed to changes in dampness content experience volumetric changes prompting pavement bending, breaking and general unevenness. The colloidal clay content in black cotton soils is up to 50percent and the portion passing $0.075 \mathrm{~mm}$ strainer ranges from 70 to 100 percent. As far as possible and plasticity list esteems ranges from 50 to 100 percent and 20 to 60 percent separately. Every one of these properties render the soil to be very delicate to dampness changes. Normal conduct of these soils under various climatic conditions has made the development and support of roads costly as well as troublesome. The pavement developed in black cotton soil regions is found to endure early disappointments. Being exceptionally sweeping soils with high plasticity these fonns poor subgrade materials. The way toward enhancing engineering properties of the soil and subsequently making it increasingly stable is called stabilization [2].

\subsection{Current Road Development Engineering}

The Geotechnical engineering division in the civil engineering office was developed in the mid 1960's. Geotechnical engineering is the examination of the conduct of soils influenced by stacking forces and soil-water affiliations. This learning is associated with the framework of foundations, holding dividers, earth dams, clay liners, and geo synthetics for waste control. The targets of geotechnical modelers could stretch out from the blueprint of foundations and passing revealing help, through course determination for railroads and roadways, to the unyieldingly crucial locales of landfill exchange of misuses and groundwater sullying. In that limit, the geotechnical configuration is related with field and research office examinations to choose the engineering properties of site soils and other geo materials and their subsequent use in the investigative investigation of the ebb and flow issue.Roads has a noteworthy impact in the enhancement of country [3]. They are help giving a smooth stream of man and materials. With the creating of people and the decreasing of open land, road overhauls and other 


\section{International Journal of Science and Research (IJSR) \\ ISSN: 2319-7064}

ResearchGate Impact Factor (2018): 0.28 | SJIF (2018): 7.426

partner building structures must be done on slight or tricky soil. Inferable from such soil of powerless shear quality and high swelling and shrinkage, a hair-raising not too awful assortment of ground change strategies, for instance, soil adjustment and support are used to overhaul mechanical lead of soil, in this manner enhancing the loyalty of enhancement. This article covers roadway enhancement in Black cotton soils (BC soils) what's more portrays a case history of interstate advancement in freeway advancement in Black cotton soils. The purpose for this investigation is to pick the perfect estimation of the stabilizer, which overhauls the quality which is suitable for black-top structure. Urbanization and present day movement in India needs to revolve around enhancement methods of interstates, railroads, air terminals and private structures.

\subsection{Light weight filling material for road development}

Foam concrete is a concrete blend that requires more noteworthy quality check to ensure the whole movement of its hugeness. The void rounding application has ended up being increasingly indisputable in light of its related course of action of central focuses like warm assurance, its rigid nature, and controlled water ingestion properties. Ground instability issue is an issue generally looked by old mines and sections. They have now used foamed concrete to fill the voids as a response for recoup reliability in sewers, advantage channels and various roadway structures like in trams and ducts [4].

\section{- Foam concrete}

Foam concrete is a kind of lightweight concrete that is produced using cement, sand or fly fiery remains, water, and the foam. Foam concrete is as foamed grout or foamed mortar. Foam concrete can be described as a cementitious material that involves least 20 percent of foam that is mechanically entrained into the plastic mortar. The dry thickness of foamed concrete may change from 300 to 1600 $\mathrm{kg} / \mathrm{m} 3$. The compressive quality of foam concrete chose at 28 days, ranges from 0.2 to $10 \mathrm{~N} / \mathrm{mm} 2$ or can go higher.

Foam concrete is isolated from air entrained concrete the extent that the volume of air that is entrained. The air entrained concrete takes in the disposition of 3 to 8 percent. It furthermore differs from the blocked mortar and flowed air through concrete for a comparable reason of level of air entrained [5]. By virtue of impeded mortar structures, it is 15 to 22 percent. The air pockets are falsely confined by virtue of a coursed air through concrete.

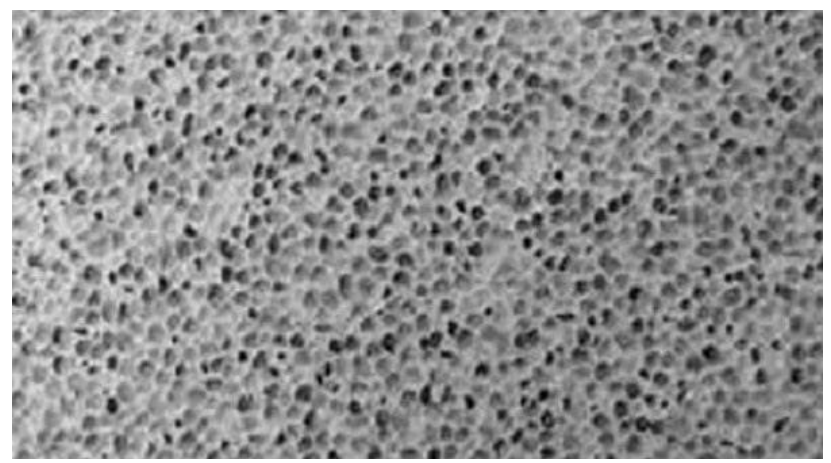

Figure 1: Foam concrete image

\section{Black Cotton Soil}

Black cotton soil is one of critical soil stores of India. They demonstrate height rate of swelling and shrinkage when displayed to changes in soddenness content and therefore have been seen to be most troublesome from engineering thought.

The rate of montmorillonite is more in black cotton soil which causes expansiveness and split occurs in soil with no notice which is hazardous for improvement. Swelling soils, generally called broad soils, are ones that swell in volume when presented to clamminess [6]. These swelling soils consistently contain earth minerals that pull in and ingest water. Exactly when water is familiar with expansive soils, the water particles are maneuvered into gaps between the soil plates. As more water is ingested, the plates are obliged additionally isolated, provoking an extension in soil pore weight. This lead is attributed to the proximity of mud minerals with developing cross section structure. Among them, Montmorrillonite earth mineral is especially powerful and holds water customarily more than its volume. The soil is hard as long as it is dry yet loses its strength about absolutely on wetting. On drying, the soil breaks gravely as showed up and in the most negative situations, the width of parts is appropriate around $150 \mathrm{~mm}$ besides, make an outing down to $3 \mathrm{~m}$ underground measurement. Broad soils are normal tropical game plans, all things considered found in insufficiently exhausted districts where there are stepped wet and dry seasons. The mud minerals are confined through broad physical and creation continuing of parent material [7].

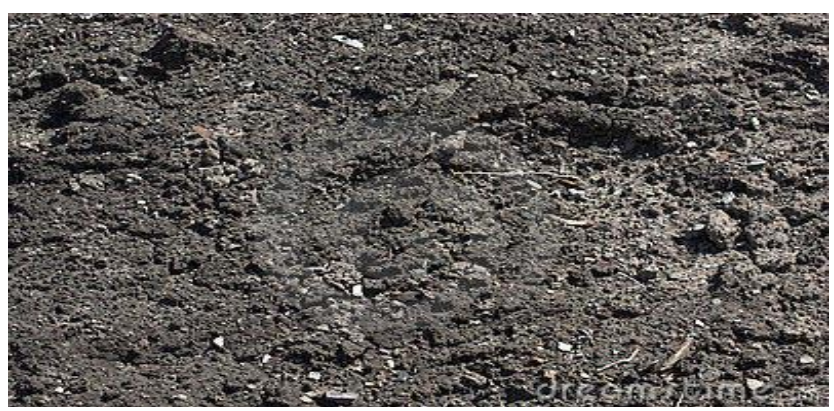

Figure 2: Black cotton soil

\section{Objectives}

The main objectives of the research paper are as follows:

1) To study the Porosity measurements and pore size of Foam Concrete

2) To study effects on FC due to high temperature

3) To study effects on compressive quality of FC due to High temperature

\section{Methodology}

The unstressed test procedure was grasped for solace. In the unstressed test, the test was warmed, without preload, at an immovable rate to the destined temperature. While keeping up the goal temperature, stack was associated at a suggested rate until test disillusionment.

Since the temperature is unaltered, the test is also implied as reliable state test, rather than transient test in which the 


\section{International Journal of Science and Research (IJSR) \\ ISSN: 2319-7064}

ResearchGate Impact Factor (2018): 0.28 | SJIF (2018): 7.426

model temperature changes with time. FC with $650 \mathrm{~kg} / \mathrm{m} 3$ and $1000 \mathrm{~kg} / \mathrm{m} 3$ thickness were tossed and attempted. The nuances of the constituent material are showed up. The tests were done at encompassing temperature, 100, 200, 300, 400, 500 , and $600^{\circ} \mathrm{C}$. Compressive and three point bowing tests were finished.

\section{Analysis and Results}

\subsection{Porosity measurements and pore size}

The pore structure of cementitious material, directed by its porosity, is a tremendous trademark as it impacts the properties of the material, for instance, quality what's more, strength. The porosity could along these lines be a primary thought affecting the material properties of FC and a start to finish examine this perspective is basic to choose the associations among porosity and material properties. Generally, the mechanical properties of FC decay with growing porosity. The thickness of FC may be different for a comparative water-bond extent, through the blend of different proportions of froth, which may result in substitute porosity and void sizes [8].

Table 1: Porosity of FC obtained through Vacuum Saturation for mechanical properties test

\begin{tabular}{|c|c|c|c|c|c|}
\hline \multirow{2}{*}{$\begin{array}{c}\text { Density } \\
\left(\mathrm{kg} / \mathrm{m}^{3}\right)\end{array}$} & \multirow{2}{*}{ Sample } & \multicolumn{4}{|c|}{ Porosity\% } \\
\cline { 3 - 6 } & & Ambient & $200^{\circ} \mathrm{C}$ & $400^{\circ} \mathrm{C}$ & $600^{\circ} \mathrm{C}$ \\
\hline \multirow{3}{*}{650} & $1 / 1$ & 74.8 & 74.9 & 75.9 & 76.3 \\
\cline { 2 - 6 } & $1 / 2$ & 74.7 & 74.9 & 75.7 & 76.1 \\
\cline { 2 - 6 } & $1 / 3$ & 74.8 & 75.0 & 76.1 & 76.5 \\
\hline \multirow{3}{*}{1000} & $1 / 4$ & 49.7 & 49.0 & 52.4 & 53.4 \\
\cline { 2 - 6 } & $1 / 5$ & 50.0 & 50.4 & 52.5 & 53.7 \\
\cline { 2 - 6 } & $1 / 6$ & 50.4 & 50.7 & 52.9 & 54.1 \\
\hline
\end{tabular}

\subsection{Changes on porosity of FC due to High temperature}

Usually, the porosity of concrete based material changes when the temperature increases. These modifications in porosity can be portrayed by considering stage changes in the concrete at different temperatures. The pore size of FC chose through picture examination gadget showed in it of this hypothesis plot pictures of the inside structure of the 650 and $1000 \mathrm{~kg} / \mathrm{m} 3$ thickness FC at surrounding temperature which clearly shows that the void sizes are not uniform and the normal void size is basically an element of the FC thickness. A similar investigation of the pictures was likewise improved the situation the two densities ensuing to being introduced to high temperatures and the results demonstrate that the void size did not differ much from that at encompassing temperature [9].

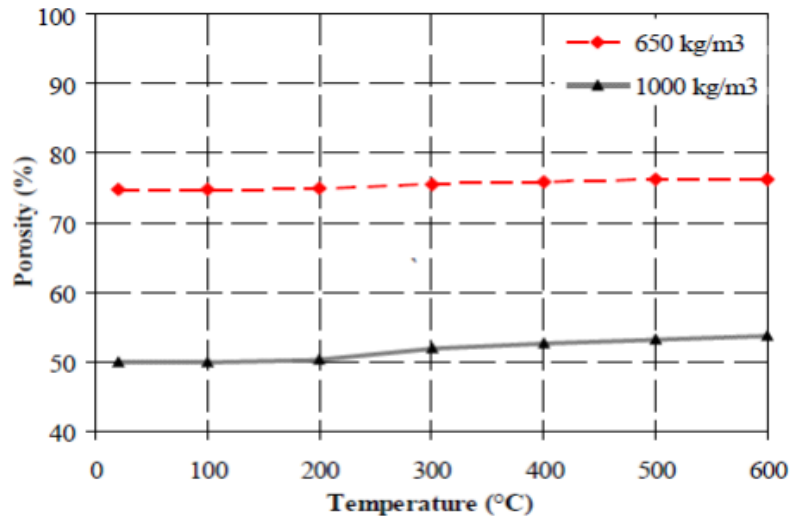

Figure 3: Porosity of LFC of two initial densities as a function of temperature

\subsection{Heating of specimens}

Two assorted electric furnaces were used for warming the FC guides to the diverse continuing state temperatures. One heater had a most outrageous working temperature of $450^{\circ} \mathrm{C}$ (low temperature heater), and the second heater had a most extraordinary working temperature of $1000^{\circ} \mathrm{C}$ (high temperature heater). All of the furnaces were set up to do holding three precedents. The low temperature heater had a temperature extent of $50^{\circ} \mathrm{C}$ to $450^{\circ} \mathrm{C}$ and was used for four of the declared warmth introduction conditions: $100^{\circ} \mathrm{C}$, $200^{\circ} \mathrm{C}, \quad 300^{\circ} \mathrm{C}$ and $400^{\circ} \mathrm{C}$. The heater temperature introduction profiles were conveyed by a programmable chip temperature controller joined to the heater control supply and checked by a Type $\mathrm{K}$ thermocouple arranged in the heater chamber. The high temperature heater had a most extraordinary working temperature of $1000^{\circ} \mathrm{C}$. This heater was used for introducing concrete guides to $500^{\circ} \mathrm{C}$ and $600^{\circ} \mathrm{C}$. This heater was furthermore constrained by a programmable microchip temperature controller affixed to the heater control supply subject to analysis temperature scrutinizing from a Type $\mathrm{K}$ thermocouple arranged in the heater chamber. Pre-testingchecking of the furnaces exhibited that both heater controllers and heater control structure could keep up heater working temperatures inside $\pm 1^{\circ} \mathrm{C}$ over the test go.

The compressive tests were finished on $100 \times 200 \mathrm{~mm}$ barrels. The precedents were ousted from molds following 24 hours of tossing and a while later mitigated in a water tank at $20 \pm 2^{\circ} \mathrm{C}$ for 28 days. Prior to testing, the precedents were removed from the soothing tank and put in the stove for 24 hours at $105^{\circ} \mathrm{C}$. Following 24 hours, all of the precedents were ousted from the oven and their completions were ground level. To screen the strain direct at encompassing temperature in the midst of stacking, two strain checks was fitted on each test for the encompassing test figuratively speaking. These incorporating temperature strain estimations were utilized to attest that the strain decided reliant on the uprooting of the stacking platen was of sufficient precision. Since it was difficult to evaluate persevere through raised temperatures, the uprooting of the stacking platen was used to register the strain for the raised temperature tests. Four Type $\mathrm{K}$ thermocouples were presented in the central plane of each barrel guide to measure the model temperature, as showed up [10]. 


\section{International Journal of Science and Research (IJSR) \\ ISSN: 2319-7064}

ResearchGate Impact Factor (2018): 0.28 | SJIF (2018): 7.426

Stacking was associated using an encompassing temperature machine ensuing to ousting the test tests from the heater. Each model was wrapped with security sheets following being removed from the electric heater to confine warm adversity from the guide to condition. For each set, three mirror tests were finished to check consistency of results. The target temperatures were $20^{\circ} \mathrm{C}$ (room temperature), 100 , $200,300,400,500$, and $600^{\circ} \mathrm{C}$.

In the midst of the stacking method, the temperature of every model (thermocouple T3) was assessed and it was found that the temperature was unfaltering all through the testing that's all anyone needs to know. It indicates normal temperature assortments all through the stacking stage for instances of $1000 \mathrm{~kg} / \mathrm{m} 3$ thickness. As can be seen, on the grounds that the term of loading was short (a little more than one moment), there was almost no heat misfortune and the temperature change was under $0.5 \mathrm{C}$.

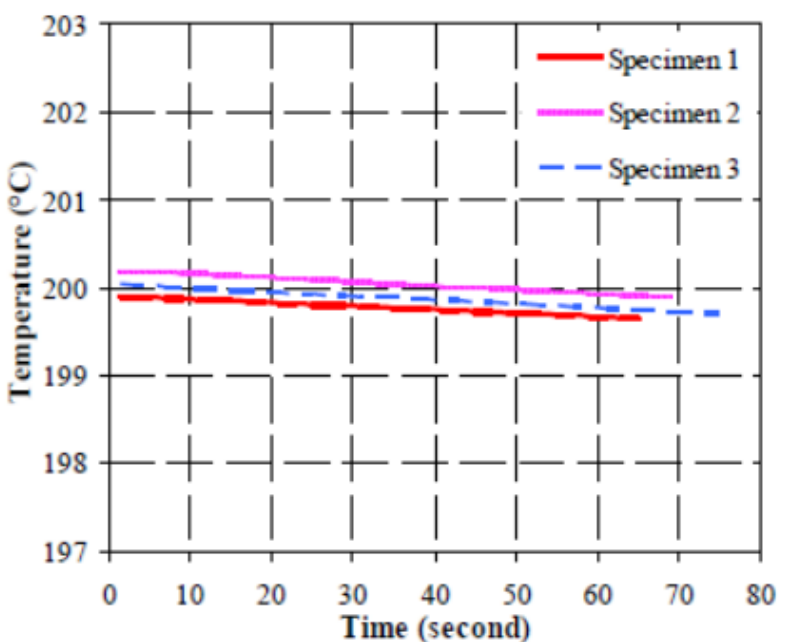

Figure 4: Change in Temperature between test of Specimens at target temperature of $200^{\circ} \mathrm{C}$ of $1000 \mathrm{~kg} / \mathrm{m} 3$ density

\subsection{Impacts of high temperature on compressive quality of FC}

The three copy trial of every arrangement gave extremely reliable outcomes so the normal outcomes might be utilized. Of course, for the two densities, the FC compressive quality decreased with temperature. It presents the compressive quality and institutionalized compressive quality of FC at unmistakable temperatures. On early on warming, the FC made with Portland concrete CEM1 lost the absorbed, evaporable (or free) water and after that the artificially bound water. The loss of water would actuate littler scale breaking realizing some decline in quality. Between $90^{\circ} \mathrm{C}$ to $170^{\circ} \mathrm{C}$, the compressive quality reduced steadily due to the release of free water and a segment of the artificially bound water. Presently, the decline in concrete quality isn't essential and the compressive quality of the FC tests at $200^{\circ} \mathrm{C}$ still held about $94 \%$ of the principal unheated regard. Between $200{ }^{\circ} \mathrm{C}$ and $400^{\circ} \mathrm{C}$, breaking down of C-S-H gel and the sulfo-aluminate stages caused splits in the precedents. These breaks effect sly affected the compressive quality of FC. At $400{ }^{\circ} \mathrm{C}$, the FC quality held just about $75 \%$ of its underlying incentive for the two densities. Further corruption and loss of solidarity proceeded to happen at high temperatures. At temperature of $600^{\circ} \mathrm{C}$, the $\mathrm{FC}$ held in a manner of speaking about $40 \%$ of the first quality for the two densities. It ought to be called attention to that in this test, heat stun ought not to be an issue. The examples were heated gradually furthermore, no heat break was seen before mechanical testing. Since the organizations of the two densities of FC are indistinguishable, with the exception of expanded pores in the lower thickness FC, it isn't astounding that the standardized quality - temperature connections of $\mathrm{FC}$ of the two densities are nearly the equivalent.

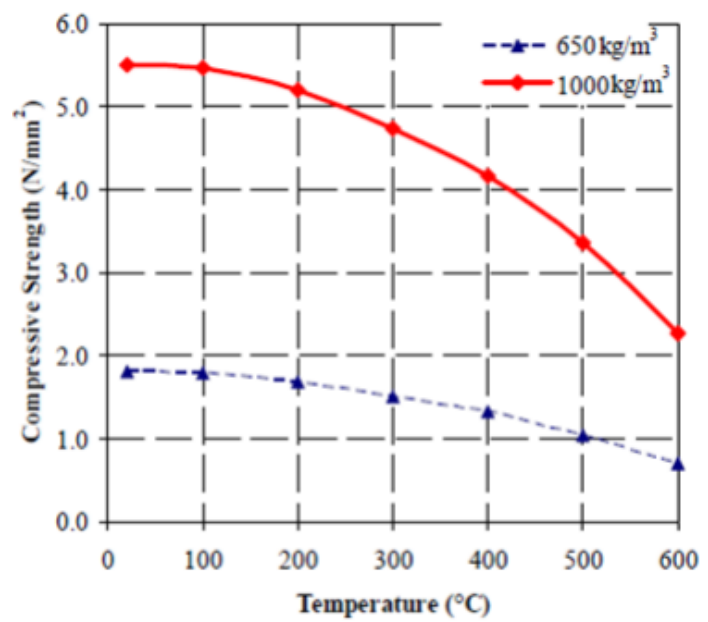

Figure 5: Compressive Strength of LFC as a function of temperature

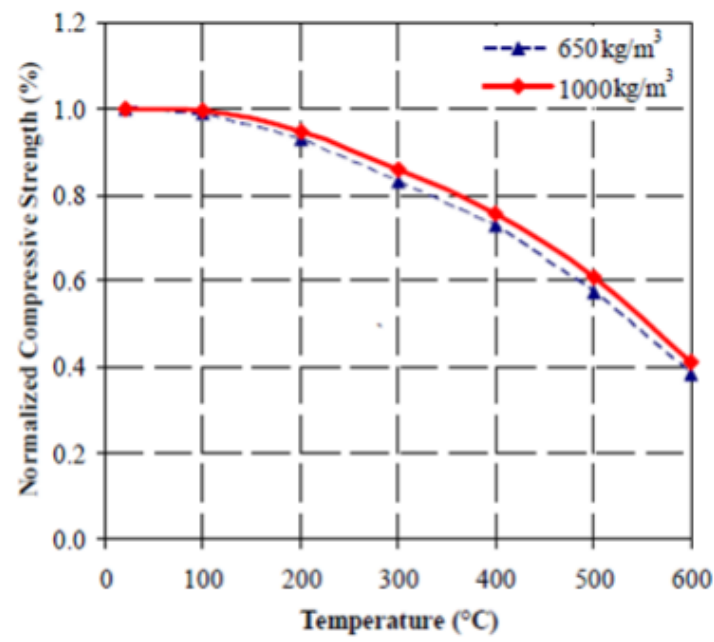

Figure 6: Representation of LFC's Normalized Compressive Strength as a function of temperature 


\section{International Journal of Science and Research (IJSR) \\ ISSN: 2319-7064}

ResearchGate Impact Factor (2018): 0.28 | SJIF (2018): 7.426

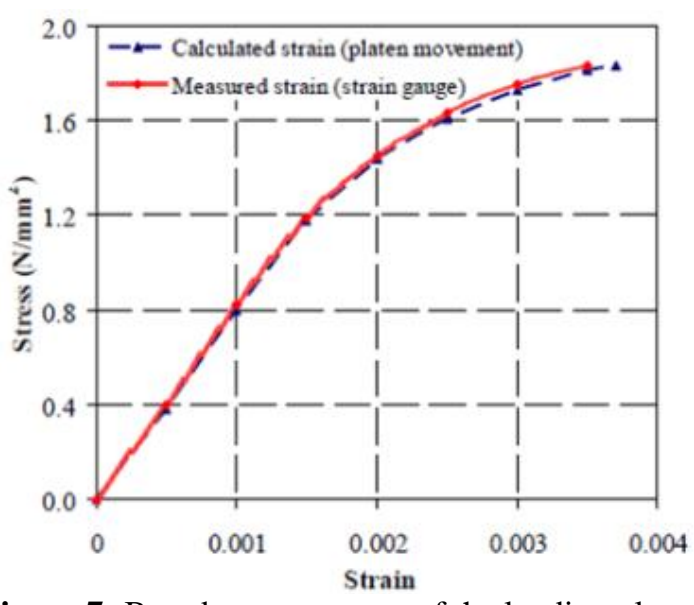

Figure 7: Based on movement of the loading platen, Comparing the calculated strain and measured strain for LFC of $650 \mathrm{~kg} / \mathrm{m} 3$ density at ambient temperature

\section{Conclusion}

Lightweight foamed concrete (LFC) was essentially utilized as a void filling and protection material however it has various ideal attributes, for example, light weight, great acoustic and protection execution, ease in manufacture, earth economical, solid and savvy. This had driven LFC to be considered as a conceivable load-bearing material for building development. The improvement of the logical strategy to decide the warm conductivity of LFC at high temperatures relied upon treating LFC as mix of dried LFC what's more, water before fulfillment of water vanishing and as mix of dried LFC and air voids a while later. The warm conductivity of dried LFC and typical air void size should be settled in order to use the illustrative model. The void size may be secured by taking a modest image of the LFC and the dried warm conductivity estimation of LFC can be clearly evaluated using the HGP test or decided whether the LFC encompassing temperature warm conductivity was accessible. This section has introduced definite direction on the best way to perform these computations. A correlation between estimated warm conductivity results utilizing the monitored hot plate test and the anticipated warm conductivity results utilizing the hypothetical model indicated great assention.

\section{References}

[1] V. C. Li, "On engineered cementitious composites (ECC)A review of the material and its applications," Journal of Advanced Concrete Technology, vol. 1, no. 3, pp. 215-230, 2003.

[2] M. S,ahmaran and V. C. Li, "De-icing salt scaling resistance of mechanically loaded engineered cementitious composites," Cement and Concrete Research, vol. 37, no. 7, pp. 1035-1046, 2007.

[3] M. Sahmaran, M. Li, and V. C. Li, "Transport properties of engineered cementitious composites under chloride exposure," ACI Materials Journal, vol. 104, no. 6, pp. 604-611, 2007.

[4] X. Luo, W. Sun, and S. Y. N. Chan, "Effect of heating and cooling regimes on residual strength and microstructure of normal strength and high-performance concrete," Cement and Concrete Research, vol. 30, no. 3, pp. 379-383, 2000.

[5] G. F. Peng, S. H. Bian, Z. Q. Guo, J. Zhao, X. Peng, and Y. Jiang, "Effect of thermal shock due to rapid cooling on residual mechanical properties of fiber concrete exposed to high temperatures," Construction and Building Materials, vol. 22, no. 5, pp. 948-955, 2008.

[6] O. Gencel, "Effect of elevated temperatures on mechanical properties of high-strength concrete containing varying proportions of hematite," Fire and Materials, vol. 36, no. 3, pp. 217-230, 2012.

[7] F. Koksal, O. Gencel, W. Brostow, and H. E. HaggLobland, "Effect of high temperature on mechanical and physical properties of lightweight cement based refractory including expanded vermiculite," Materials Research Innovations, vol. 16, no. 1, pp. 7-13, 2012.

[8] M. Sahmaran, M. Lachemi, and V. C. Li, "Assessing mechanical properties and microstructure of firedamaged engineered cementitious composites," ACI Materials Journal, vol. 107, no. 3, pp. 297-304, 2010.

[9] M. Ssahmaran, E. Ozbay, H. E. Y ' ucel, M. Lachemi, and V. C. Li, ". "Effect of fly ash and PVA fiber on microstructural damage and residual properties of engineered cementitious composites exposed to high temperatures," Journal of Materials in Civil Engineering, vol. 23, no. 12, pp. 1735-1745, 2011.

[10] V. C. Li, C. Wu, S. Wang, A. Ogawa, and T. Saito, "Interface tailoring for strain-hardening polyvinyl alcohol-engineered cementitious composite (PVAECC),"ACI Materials Journal, vol. 99, no. 5, pp. 463$472,2002$. 